\title{
ESTUDO QUANTITATIVO DO TRÂNSITO EM PONTOS CRÍTICOS DA CIDADE DE JOAÇABA/SC
}

\author{
L. A. Bulla ${ }^{1}$; G. Luvizão ${ }^{2}$; F. A. Nienov³ ; L. Q. Zampieri ${ }^{4}$ \\ ${ }^{1}$ Acadêmico do curso de Engenharia Civil da Universidade do Oeste de Santa Catarina, Joaçaba/SC \\ 2,3, 4 Professor do curso de Engenharia Civil da Universidade do Oeste de Santa Catarina, Joaçaba/SC \\ luiz@zagoassessoria.com.br ${ }^{1}$,gislaine.luvizao@unoesc.edu.br ${ }^{2}$,fabiano.nienov@unoesc.edu.br ${ }^{3}$, \\ lucas.zampieri@unoesc.edu.br ${ }^{4}$
}

\begin{abstract}
Resumo: Os problemas relacionados ao trânsito nos municípios de Joaçaba, Luzerna e Herval d'Oeste situados no estado de Santa Catarina, se agravam diariamente, acarretando na formação de filas e congestionamento. Desta forma a identificação, quantificação e qualificação dos veículos e fluxos se mostra imprescindível para o desenvolvimento e progresso do meio oeste Catarinense. Para obtenção dos dados foram realizados estudos de tráfego em quatro interseçôes no centro do município de Joaçaba, localizados em pontos críticos. Nestes pontos estudados circulam em média 33 mil veículos por dia, representando $145 \%$ da frota joaçabense, ou $80 \%$ da frota do arranjo populacional (Joaçaba, Luzerna e Herval d'Oeste). Com os dados do estudo foi possível atestar o descaso com o tipo de transporte em massa na regiáo, dos quais carros e motos representam em média $95 \%$ do trânsito, ocasionando congestionamentos e reduzindo a velocidade em horários de pico. A contagem do volume de veículos traz diversas informaçóes do tráfego de Joaçaba, podendo ser base para o planejamento de engenharia do arranjo populacional.
\end{abstract}

Palavras-chave: Mobilidade, Estudo de tráfego, Engenharia de tráfego.

Abstract: Traffic-related problems in the municipalities of Joaçaba, Luzerna and Herval d'Oeste in the state of Santa Catarina, aggravate daily, leading to queuing and congestion. In this way the identification, quantification and qualification of the vehicles and flows is essential for the development and progress of the Santa Catarina Midwest. To obtain the data, traffic studies were carried out at four intersections in the center of the city of Joaçaba, located at critical points. In these points, an average of 33,000 vehicles per day, representing $145 \%$ of the Joaçabense fleet, or $80 \%$ of the population arrangement (Joaçaba, Luzerna and Herval d'Oeste) circulate on average. With the data from the study it was possible to attest to the disregard for the type of mass transportation in the region, of which cars and motorcycles represent on average $95 \%$ of the traffic, causing congestion and reducing the average speed at peak times. The volume counting of vehicles brings diverse information of the traffic of Joaçaba, being able to be basis for the engineering planning of the population arrangement.

Keywords: Mobility, Traffic Study, Traffic Engineering. 


\section{Introduçáo}

O Brasil na década de 70 sofreu um grande processo de urbanização. No estado de Santa Catarina, por exemplo, deu-se início ao êxodo rural, na época a população rural representava $57 \%$ do total, enquanto atualmente caiu para $16 \%$ [1].

O aglomerado urbano Joaçaba, Herval d'Oeste e Luzerna apresentavam em 1960 aproximadamente 34 mil habitantes, passando a ter aproximadamente 54 mil habitantes em 2010, mostrando-se municípios altamente urbanos, de acordo com o padrão catarinense [1].

O planejamento urbano tradicional, concentra-se em apenas uma parte do sistema, por ser uma rede complexa de sistemas que interagem. A distribuição desigual dos benefícios por parte das organizaçóes, a falta de um sistema adequado e iterativo e a adoção de modelos convencionais, causam atrasos de congestionamento para os veículos ou barreiras para os pedestres [2]

A regiáo de Joaçaba enfrenta desafios para o planejamento viário, onde destaca-se o relevo acidentado, ruas estreitas, o Rio do Peixe que delimita os municípios de Joaçaba e Herval d Oeste, o alto fluxo de veículos e a falta de planejamento urbano entre as duas cidades. Para mudar o panorama atual, é preciso que se invistam em estudos e além de soluções e ações para reduzir os congestionamentos, melhorando a circulação de cargas e pessoas.

\subsection{Estabelecimento das zonas de tráfego}

A delimitação das zonas de tráfego é feita por aproximações sucessivas. Em princípio, os polos de geração e de atração de viagens devem ser identificados com os municípios e o seu conjunto ser enquadrado, quando possível, dentro dos limites das microrregiôes homogêneas (limites políticos, administrativos e censitários) [3].

\subsection{Arranjos populacionais}

Arranjos populacionais são unidades espaciais que arranjam em diferentes magnitudes e ocorrem deslocamentos pendulares de grande importância, principalmente na ampliação da área construída e no trabalho. São impulsionados pela crescente atividade dinâmica entre as cidades, incorporação de novas áreas residenciais, a busca por emprego e a oferta de transporte mais eficiente [4].

Há 294 arranjos populacionais no pais, formado por 938 municípios, que representam 55,9\% da populaçáo residente no País em 2010. No meio oeste catarinense temos dois arranjos populacionais, Joaçaba e Capinzal [1]. Os municípios de Joaçaba, Herval d'Oeste e Luzerna formam um arranjo populacional, demonstrando na Tabela 1. 
Tabela 1 - Arranjo populacional.

\begin{tabular}{ccccc}
\hline Municípios & Populaçáo & Núcleo $^{1}$ & $\begin{array}{c}\text { Pessoas que trabalham } \\
\text { e estudam em outros } \\
\text { municípios do arranjo }\end{array}$ & $\begin{array}{c}\text { Mancha Urbanizada } \\
\text { Contígua }^{2}\end{array}$ \\
\hline Herval d'Oeste & 21.239 & Sim & 7.403 & Sim \\
Joaçaba & 27.020 & Sim & 8.037 & Sim \\
Luzerna & 5.600 & Não & 1.562 & Sim \\
\hline \multicolumn{5}{c}{ Fonte: adaptado IBGE (2010). } \\
${ }^{1}$ Indica se o município faz parte do núcleo do arranjo ou não. ${ }^{2}$ É preenchida com "sim” para as distâncias até $3 \mathrm{km.}$
\end{tabular}

\subsection{Movimentos pendulares}

Os movimentos pendulares além de constituírem um fenômeno complexo, por se inter-relacionar com os distintos fatores determinantes da mobilidade espacial da população que estão, por sua vez, associados direta e indiretamente a um sistema de carências e de necessidades referidas ao cotidiano da população. Em consequência, manifestam-se por diferentes níveis escalares cujos paramentos podem ser abalizados, por exemplo, em relação a [1]:

a. urbanização/metropolização - responsáveis por novas e diferentes formas de mobilidade;

b. migração (regional e inter-regional);

c. mobilidade cotidiana e a mobilidade residencial;

d. despesas com viagens e renda obtidas através do trabalho;

e. o nível de escolaridade;

f. o nível de renda;

g. as viagens de negócios e eventos sociais atribuídos normalmente a eventos turísticos;

h. consultoria, assessoria e outras atividades oferecidas por profissionais prestadores de serviços especializados.

Joaçaba é a cidade com a segunda maior taxa de atração do Estado, com 30,85\%. Herval d'Oeste e Luzerna, que formam o arranjo populacional apresentam elevadas taxas de repulsão, Herval d'Oeste com 35,99\%.

Analisando o arranjo populacional de Joaçaba e Herval d'Oeste, caracterizou as tipologias de taxa de atração e repulsão: 
a. para Joaçaba - Municípios com elevadas taxas de atração e baixas taxas de repulsão, ou seja, conseguiam reter a sua população empregada e ao mesmo tempo atrair população de fora;

b. para Herval d'Oeste e Luzerna - Municípios com elevadas taxas de repulsão e baixas taxas de atração, ou seja, não possui uma dinâmica econômica satisfatória para atender sua demanda por emprego.

Geralmente os municípios que apresentam altas taxas de atração são aqueles que sofrem pressão sobre as estruturas econômicas e de serviços, e os que apresentam altas taxas de repulsão sofrem pressão na esfera social, sinalizando a função de municípios-dormitórios [5].

\section{Metodologia}

Neste capítulo são apresentados os materiais e métodos utilizados na elaboração do estudo de quantificação do volume de tráfego em pontos críticos no centro da cidade de Joaçaba. Buscou-se analisar o comportamento do trânsito nas principais ruas de Joaçaba, Av. Santa Teresinha e Av. XV de Novembro. A pesquisa teve caráter científico e exploratório, apresentando resultados de análises estatísticas e do comportamento do trânsito.

O município de Joaçaba está localizado no meio oeste do Estado de Santa Catarina, é cortada pelas rodovias BR-282 e a SC-150, a rodovia estadual serve como ligação entre os municípios de Luzerna e Joaçaba, no perímetro urbano recebe o nome de Avenida Santa Terezinha, da qual passa pelo centro de Joaçaba unindo os tráfegos municipal e rodoviário.

\subsection{Estabelecimento das áreas de estudo}

O critério de escolha da área de estudo foi o volume de tráfego de veículos e pessoas, importância para o fluxo e ocorrência de congestionamentos (Figura 1 e Figura 2).

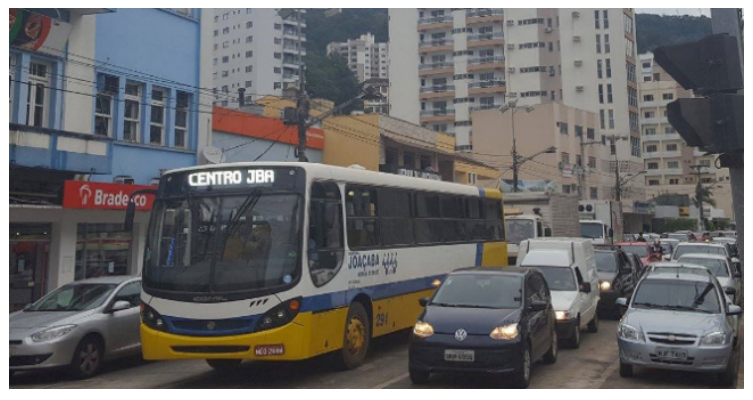

Figura 1 - Av. Santa Teresinha.

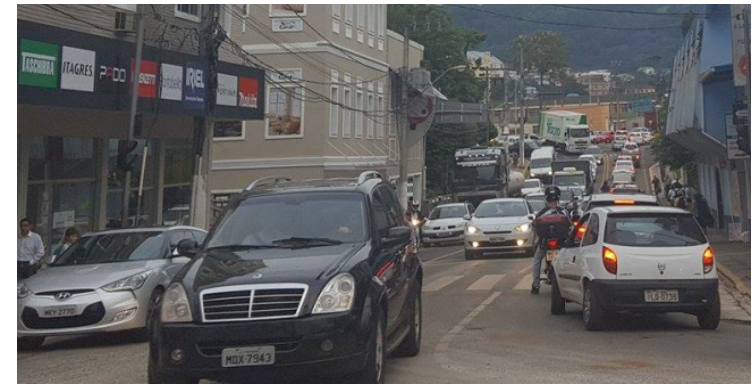

Figura 2 - Rua Getúlio Vargas. 
Devido ao grande fluxo, complexidade e canalização do tráfego no centro da cidade de Joaçaba, foram escolhidos quatro pontos críticos (Figura 3) nas duas principais avenidas da cidade.

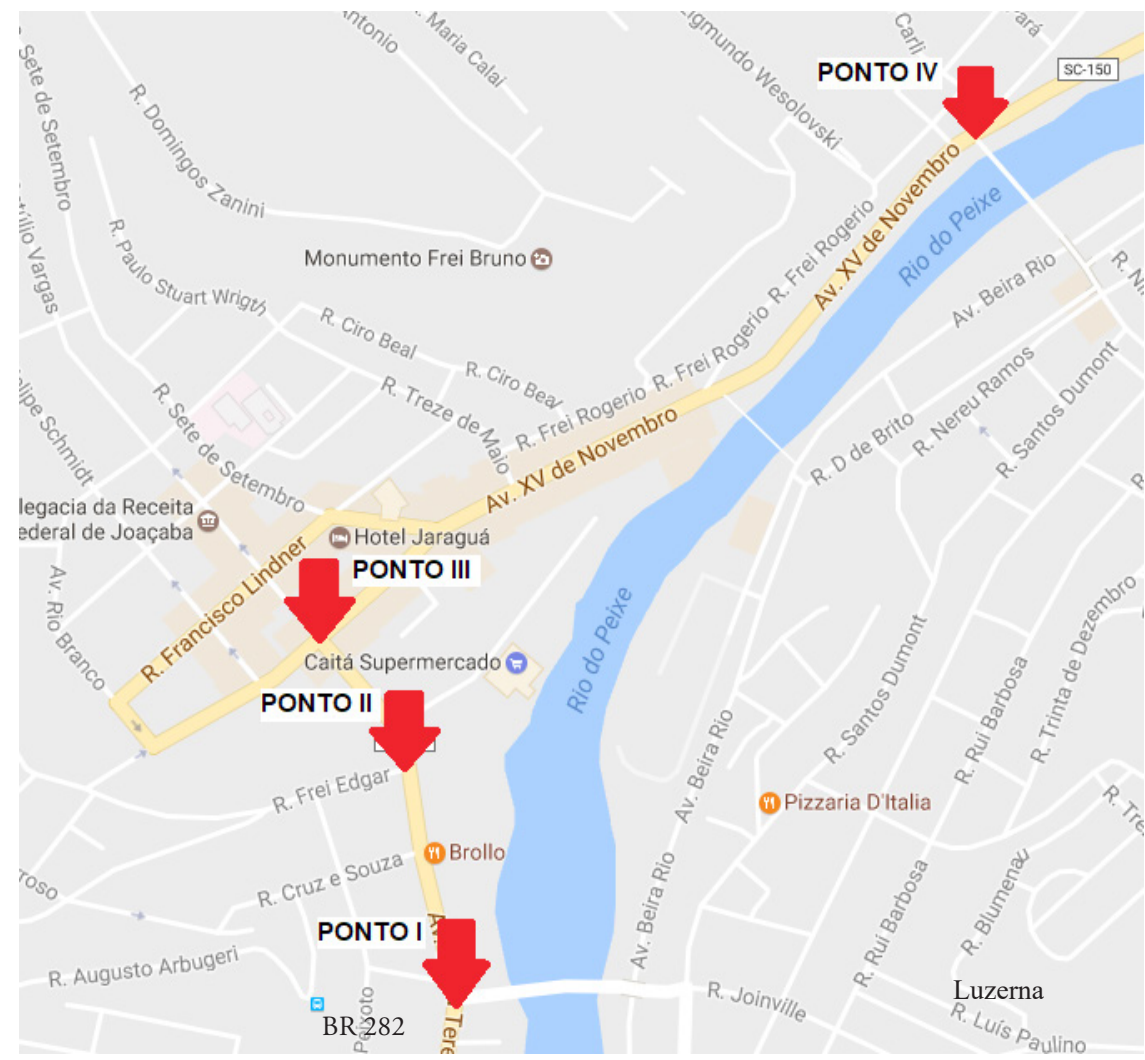

Figura 3 - Mapa com os pontos de levantamento.

Fonte: adaptado Google Earth.

\subsection{Contagens volumétricas}

Para efetuar a análise das vias foram realizadas contagens de veículos utilizando videoteipe da 10a Central Regional de Emergência (CRE), situada em Herval d'Oeste e fichas de contagens volumétricas. As contagens foram efetuadas nos quatro locais, durante três dias da semana, em três horários distintos: 6h30, 11 h00 e 17h00. As contagens diárias tiveram duração de 8 horas, ou seja, contagem de um "período de pico" dentro da hora que constitui um maior tráfego de veículos. Os dias das contagens foram sequenciais e em dias de semana, na terça-feira, quarta-feira e quinta-feira. Os veículos foram separados em carros de passeio, motos, caminhóes e ônibus. Em todos os dias de levantamento, o clima se apresentava bom e ensolarado sem ocorrência de chuvas.

Para calcular o volume médio diário das interseções foi necessário conhecer o volume de veículos passantes nas $24 \mathrm{~h}$ do dia, solicitou-se junto a Prefeitura Municipal de Joaçaba as contagens diárias do ano de 2016 realizadas pelas lombadas eletrônicas, tendo os dados e as localizaçôes das lombadas, identificou-se que o aparelho JO003 instalado em frente ao Colégio Celso Ramos, que regulamentava o sentido bairro - centro, coincide com o FG 03 do Ponto II. 
Para fazer a extrapolação com dados coerentes foi adotado estes requisitos: três meses distintos: março, junho e setembro; dias da semana iguais ao do levantamento: terça, quarta e quinta feira; semanas sem feriado; sem ocorrência de chuvas durante a semana.

\section{Resultados}

Com os levantamentos de campo e análise dos dados coletados por videoteipe, obtiveram-se as características de sinalização e direção de fluxo (Figuras 4, 6, 8 e 10), além dos valores de volume de tráfego no horário de pico, conforme apresentado nas Figuras 5, 7, 9 e 11.

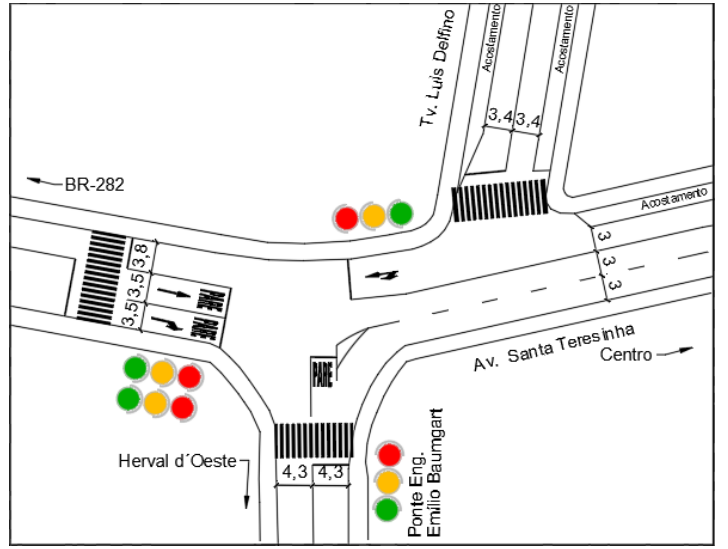

Figura 4 - Características Ponto I.

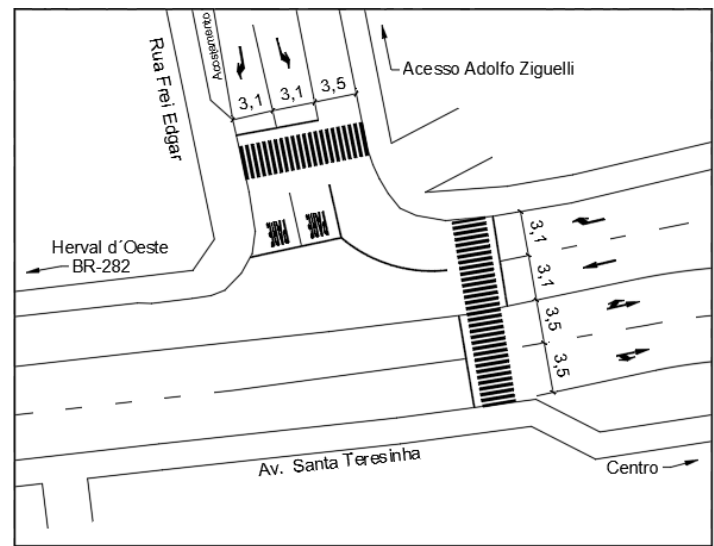

Figura 6 - Características Ponto II.

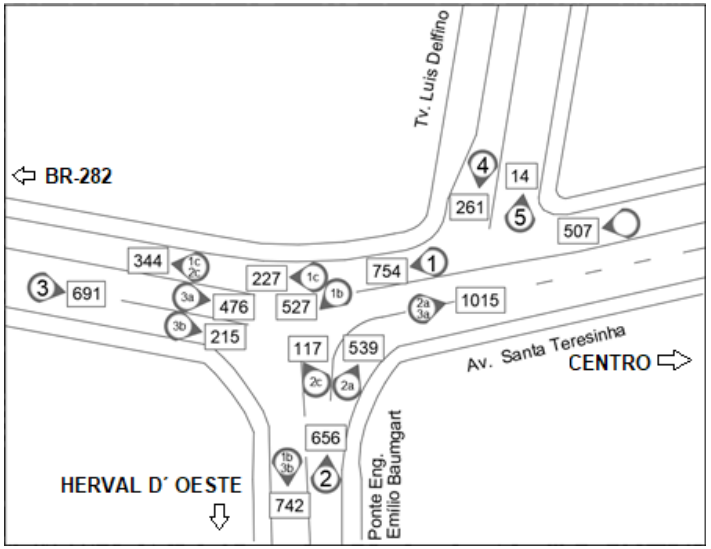

Figura 5 - Veículos hora pico Ponto I.

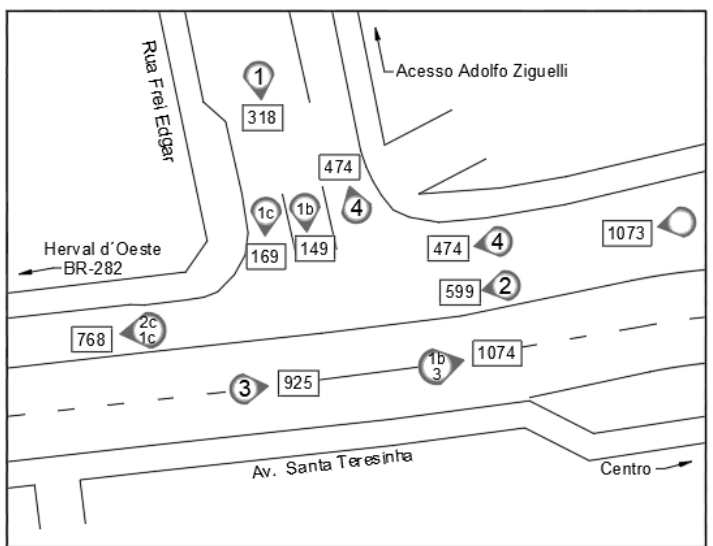

Figura 7 - Veículos hora pico Ponto II. 


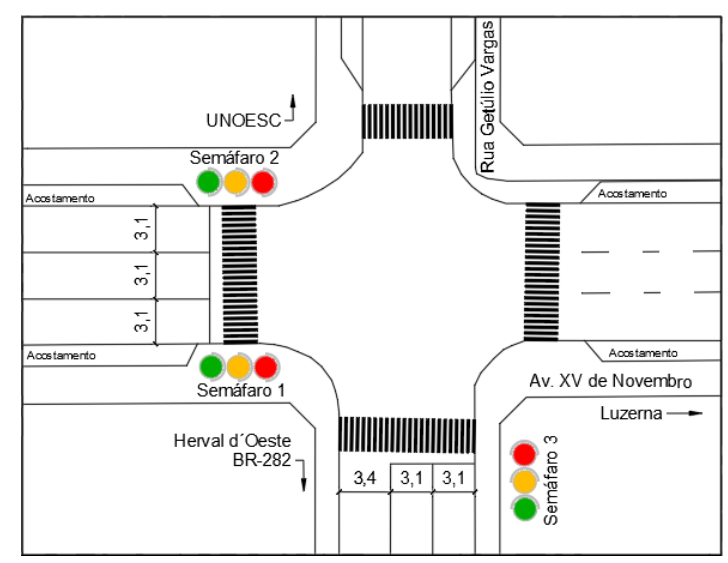

Figura 8 - Características Ponto III.

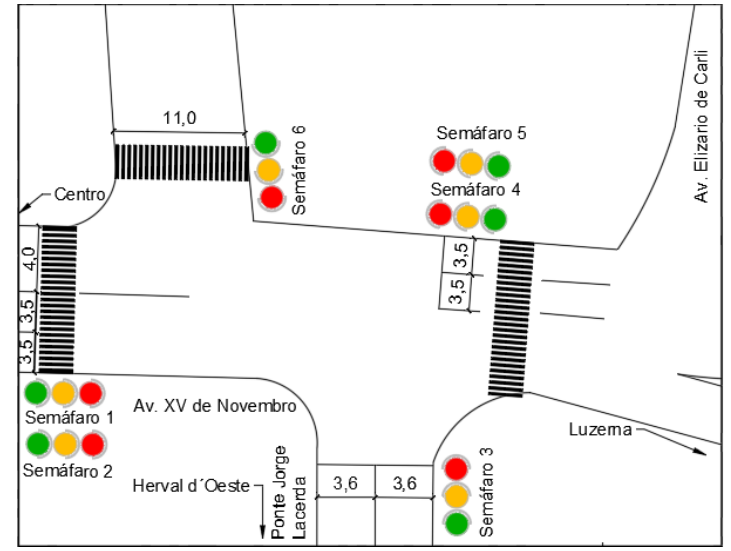

Figura 10 - Características Ponto IV.

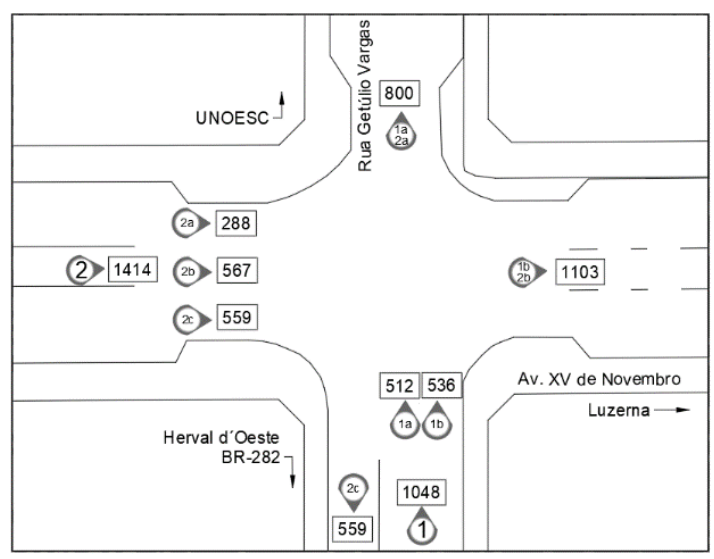

Figura 9 - Veículos hora pico Ponto III.

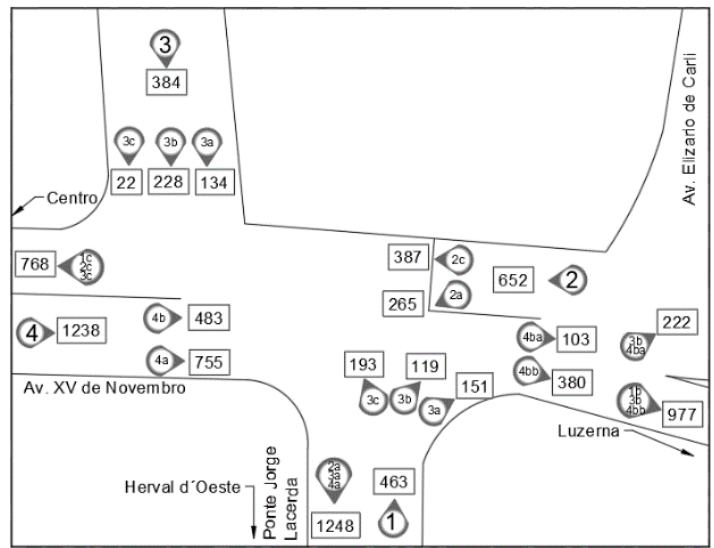

Figura 11 - Veículos hora pico Ponto IV.

A contagem volumétrica das lombadas eletrônicas separa de forma idêntica ao levantamento manual os veículos, caracterizando em quatro categorias: carros, motos, caminhóes e ônibus.

Para encontrar o volume aproximado característico da via, foi realizada a média das contagens volumétricas dos três meses analisados. No Gráfico 1 está demonstrado o volume médio de veículos passantes na lombada eletrônica JO003, apenas no sentido BR-282 para o centro de Joaçaba.

Nota-se que na lombada eletrônica o horário das $18 \mathrm{~h}$ até $19 \mathrm{~h}$ é o horário de pico com 852 veículos passantes. Para extrapolar os dados das contagens, foi utilizando percentual de cada horário sobre o horário de pico, a Tabela 2 apresenta o detalhamento dos volumes por horário. 


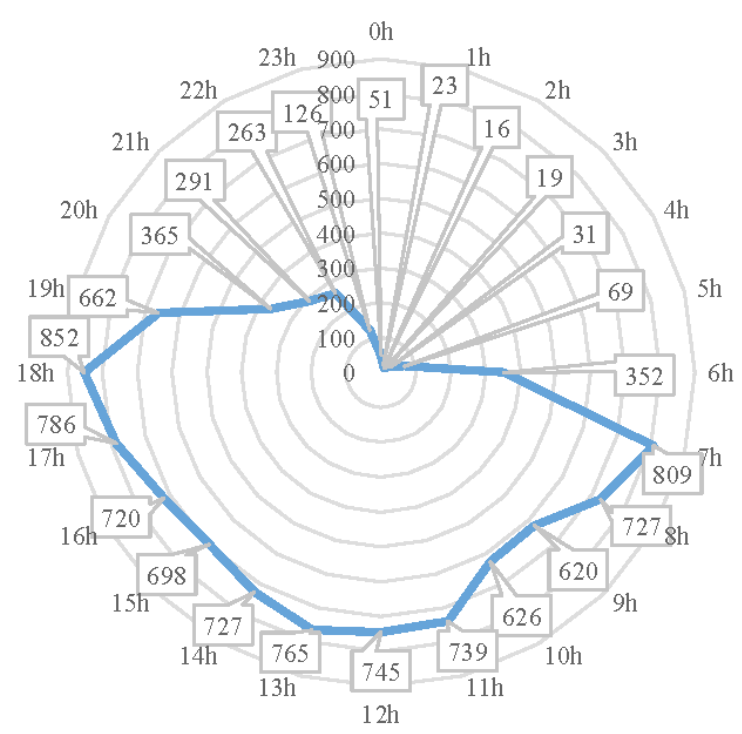

Gráfico 1 - Volume horário - JO003 Sentido BR-282 para centro Joaçaba.
Tabela 2 - Relação Volume de Pico.

\begin{tabular}{|c|c|c|}
\hline \multicolumn{2}{|c|}{ Horário } & \multirow{2}{*}{$\begin{array}{c}\text { Hora/Hora Pico } \\
5,98 \%\end{array}$} \\
\hline 00:00 & 01:00 & \\
\hline 01:00 & 02:00 & $2,66 \%$ \\
\hline 02:00 & 03:00 & $1,84 \%$ \\
\hline 03:00 & 04:00 & $2,23 \%$ \\
\hline 04:00 & 05:00 & $3,68 \%$ \\
\hline 05:00 & 06:00 & $8,13 \%$ \\
\hline 06:00 & 07:00 & $41,34 \%$ \\
\hline 07:00 & 08:00 & $94,92 \%$ \\
\hline 08:00 & 09:00 & $85,30 \%$ \\
\hline 09:00 & $10: 00$ & $72,74 \%$ \\
\hline $10: 00$ & $11: 00$ & $73,45 \%$ \\
\hline $11: 00$ & $12: 00$ & $86,70 \%$ \\
\hline $12: 00$ & $13: 00$ & $87,45 \%$ \\
\hline $13: 00$ & $14: 00$ & $89,79 \%$ \\
\hline $14: 00$ & $15: 00$ & $85,30 \%$ \\
\hline $15: 00$ & $16: 00$ & $81,89 \%$ \\
\hline $16: 00$ & $17: 00$ & $84,47 \%$ \\
\hline $17: 00$ & $18: 00$ & $92,18 \%$ \\
\hline $18: 00$ & $19: 00$ & $100,00 \%$ \\
\hline $19: 00$ & $20: 00$ & $77,67 \%$ \\
\hline $20: 00$ & $21: 00$ & $42,78 \%$ \\
\hline $21: 00$ & $22: 00$ & $34,14 \%$ \\
\hline $22: 00$ & 23:00 & $30,86 \%$ \\
\hline $23: 00$ & 00:00 & $14,82 \%$ \\
\hline
\end{tabular}

Observa-se o grande fluxo de veículos entre as 7 h e $19 \mathrm{~h}$, variando entre 620 e 850 veículos por hora. Considerado fluxo intenso, sendo este valor referente apenas um sentido de fluxo para uma via com pista simples.

O mesmo comportamento foi identificado nos 4 pontos analisados. Com isso elaborou-se o diagrama horário e um esquema diário do fluxo de veículos (Gráficos 2, 3, 4 e 5, Figuras 12, 13, 14 e 15). 

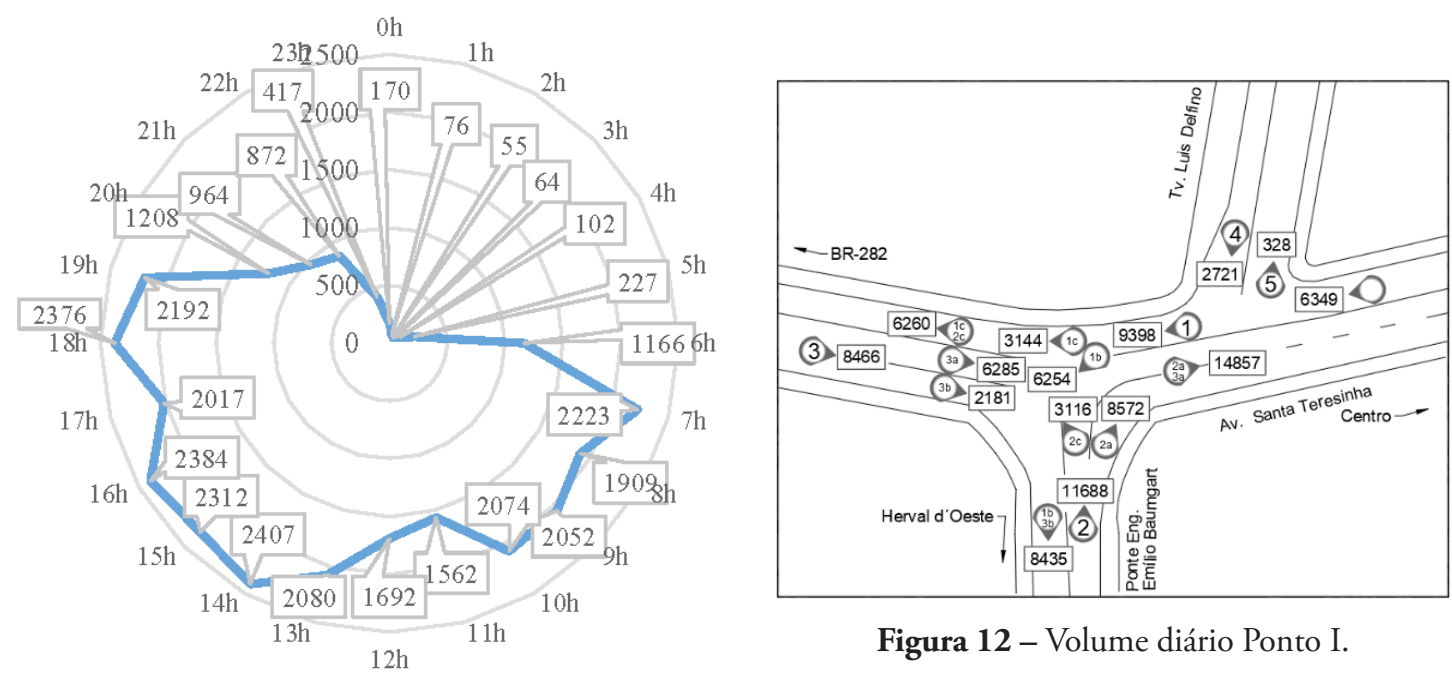

Figura 12 - Volume diário Ponto I.

Gráfico 2 - Volume horário Ponto I.
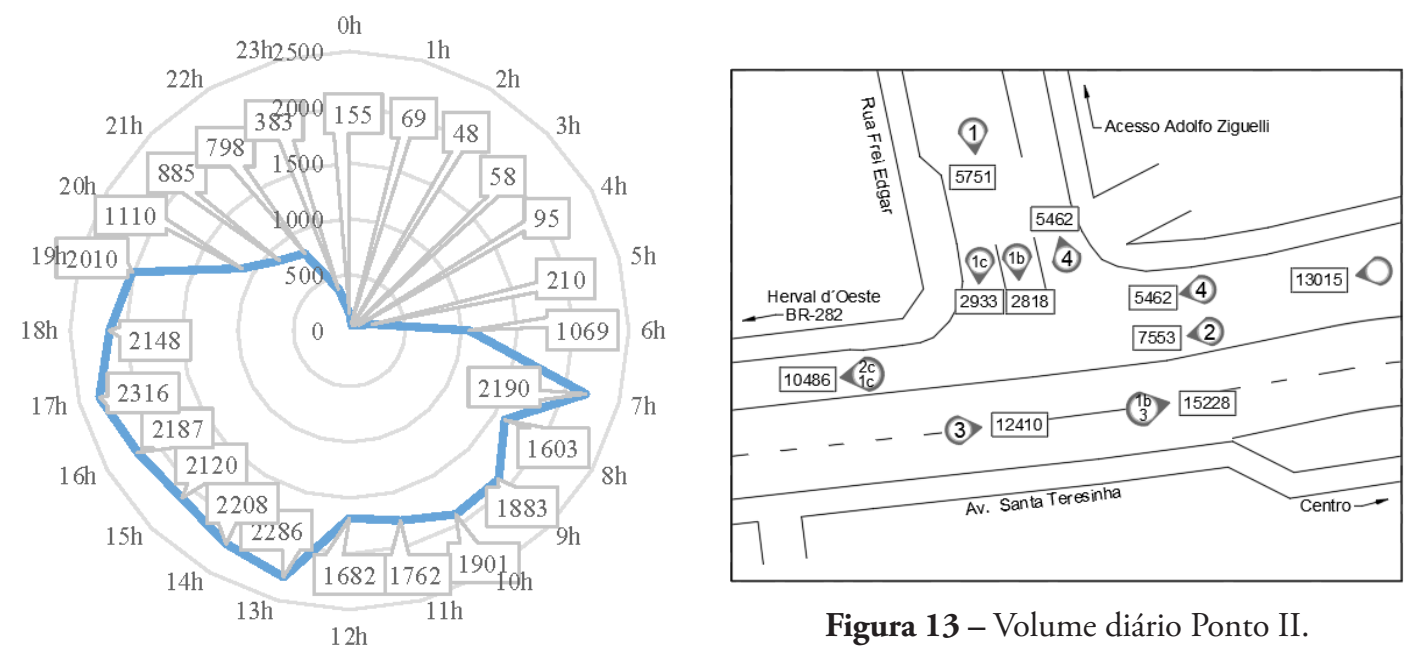

Figura 13 - Volume diário Ponto II.

Gráfico 3 - Volume horário Ponto II.

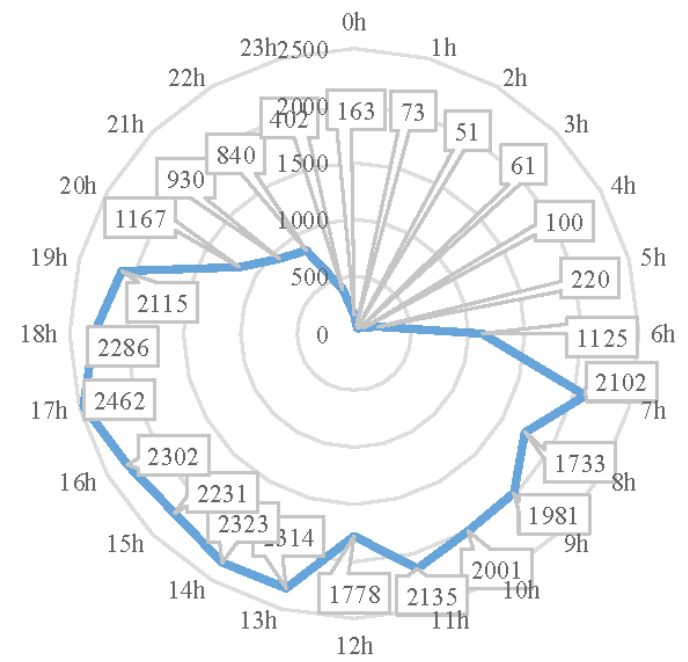

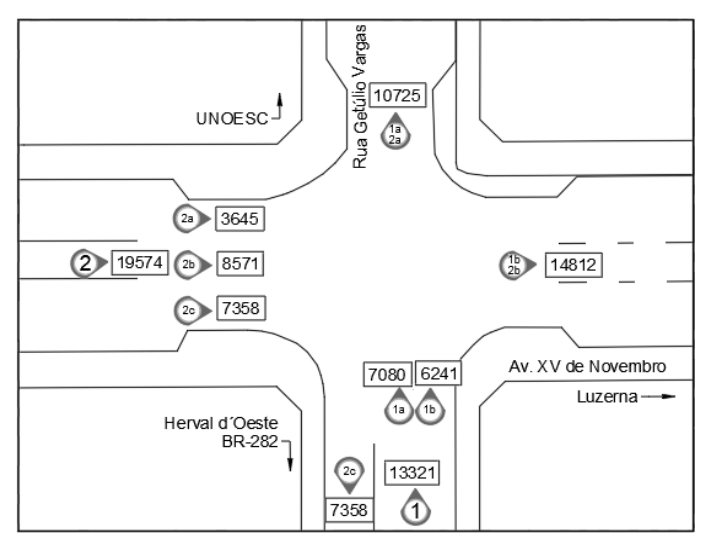

Figura 14 - Volume diário Ponto III.

Gráfico 4 - Volume horário Ponto III. 


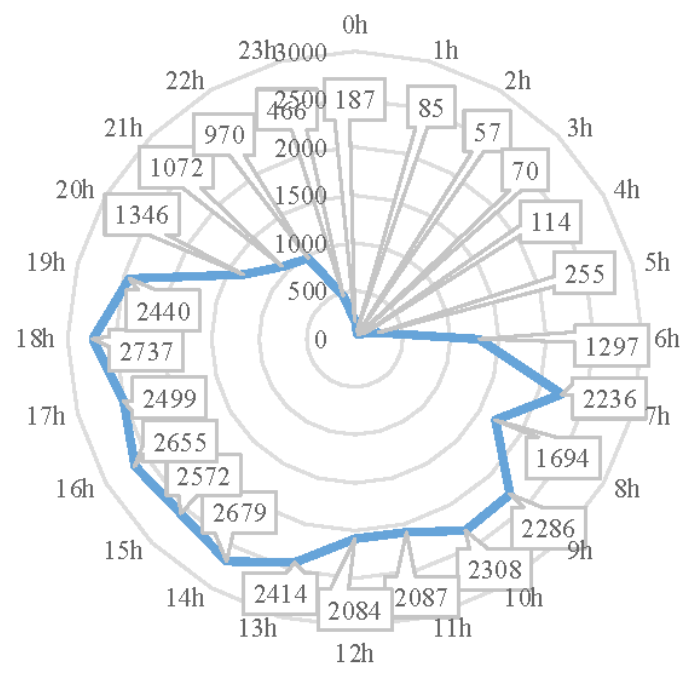

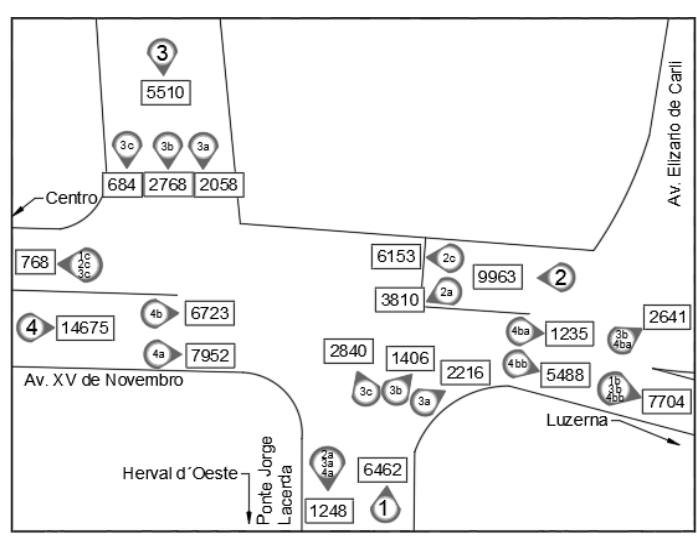

Figura 15 - Volume diário Ponto IV.

Gráfico 5 - Volume horário Ponto IV.

Após a contagem e extrapolação dos dados, destaca-se que nos pontos estudados a média de 33 mil veículos por dia, representando segundo DENATRAN [6], 145\% da frota Joaçabense ou 80\% da frota do arranjo populacional. Outro dado expressivo é o uso de carros e motos no trânsito de Joaçaba, representando $95 \%$ dos veículos que transitam nos pontos estudados.

\section{Conclusóes}

Ao término deste estudo pode-se aferir que a contagem de tráfego realizada, demonstra o descaso dos transportes em massa na regiáo. Do total geral os automóveis e motos representam em média 95\% do trânsito, ocasionando congestionamentos e reduzindo a velocidade média em horários de pico, o que representa redução de $75 \%$ da capacidade da via.

As longas filas nas avenidas e ruas, acidentes e consequentemente a redução da qualidade de vida de seus moradores e visitantes, mostra a falta de investimentos públicos em desenvolver políticas de mobilidade urbana e traçar planos para alcançar o desenvolvimento de maneira ordenada.

Antecipar o futuro permite identificar questôes urgentes, estar preparados e gerar informaçóes confiáveis sobre a necessidade da população, das quais existem estratégias que podem ser adotadas, como: incentivo ao ciclismo e à caminhada; incentivo ao transporte público; realizaçáo de campanhas para incentivar os estudantes a usar o transporte público; melhoria da infraestrutura voltada para o transporte público e não motorizado na cidade; realização de campanhas sobre o uso do consciente do automóvel particular; restrição ao estacionamento de veículos particulares na área central da cidade; aumento de preços do estacionamento na zona azul; e eliminação de vagas nas vias públicas e construção de edifícios-garagem a serem operados por empresas privadas para prover vagas de estacionamento. 
Portanto, fica evidente a necessidade planejamento urbano conjunto entre o arranjo populacional Joaçaba, Herval d'Oeste e Luzerna, pois somente com estudos e implementaçôes de semáforos, rotulas e principalmente o uso de transporte em massa na região, os problemas ocasionados pelo grande fluxo de veículos poderá reduzir.

\section{Referências}

[1] IBGE. Instituto Brasileiro de Geografia e Estatística. Censo demográfico 2010. Disponível em: <http://www.ibge. gov.br/home/estatistica/populacao/censo2010/default.shtm>. Acesso em: 10 nov. 2017.

[2] Hellem de Freitas Miranda, Antonio Nelson Rodrigues da Silva. Benchmarking sustainable urban mobility: The case of Curitiba, Brazil. Transport Policy. p. 141-151, 2012.

[3] DNIT. Departamento Nacional de Infraestrutura de Transporte. Manual de Estudos de Tráfego. 2006.

[4] IBGE. Instituto Brasileiro de Geografia e Estatística. Arranjo Populacionais e Concetraçóes Urbanas em Santa Catarina. Disponível em: <ftp://geoftp.ibge.gov.br/organizacao_do_territorio/tipologias_do_territorio/arranjos_ populacionais/mapas_2ed/mapa122.pdf>. Acesso em: 8 nov. 2017.

[5] Marley Vanice Deschamps. Análise dos movimentos pendulares nos municípios de Santa Catarina: uma abordagem regional. 2. ed. - UNC/IPARDES, 2008.

[6] DENATRAN. Departamento Estadual de Trânsito de Santa Catarina. Estatística de veículos. Disponível em: <http://consultas.detrannet.sc.gov.br/Estatistica/Veiculos/winVeiculos.asp?lst_municipio=8177\&nome_ munic=JOACABA\&lst_ano=2017\&lst_mes=0>. Acesso em: 15 nov. 2017. 